Discussion Paper No. 807

\title{
THE EFFECTS OF NON-ASSERTION OF PATENTS PROVISIONS: \\ R\&D INCENTIVES IN VERTICAL RELATIONSHIPS
}

\author{
Noriaki Matsushima \\ Koki Arai \\ Ikuo Ishibashi \\ Fumio Sensui
}

April 2011

The Institute of Social and Economic Research Osaka University

6-1 Mihogaoka, Ibaraki, Osaka 567-0047, Japan 


\title{
The effects of non-assertion of patents provisions: $R \& D$ incentives in vertical relationships*
}

\author{
Noriaki Matsushima ${ }^{\dagger}$ \\ Institute of Social and Economic Research, Osaka University \\ Koki Arai ${ }^{\ddagger}$ \\ Competition Policy Research Center, Japan Fair Trade Commission \\ Ikuo Ishibashi ${ }^{\S}$ \\ Osaka School of International Public Policy, Osaka University \\ Fumio Sensui \\ Graduate School of Law, Kobe University
}

April 15, 2011

\begin{abstract}
Using a simple downstream duopoly model with vertical relations and downstream $\mathrm{R} \& \mathrm{D}$, we investigate the effect of non-assertion of patents (NAP) provisions. A monopoly upstream firm decides whether to employ NAP provisions. If it does so, it freely incorporates the R\&D outcomes into its inputs. Incorporation improves the efficiency of the downstream firms' production. We have interpreted the introduction of NAP provisions as a source of technology spillover. Using the technologies of two downstream firms is optimal for the upstream firm if and only if the degree of technology spillover is small. In addition, if the ex ante cost difference between the downstream firms is significant, such technology spillovers erode both the profit of the efficient downstream firm and social welfare. We interpret our result in the context of an actual antitrust case related to this model.
\end{abstract}

Keywords: vertical relations, investment, technology spillover, NAP provisions

\section{JEL Classification codes: K43, L11}

${ }^{*}$ The views expressed herein are those of the authors and should not be interpreted as those of the Japan Fair Trade Commission.

${ }^{\dagger}$ Corresponding author: Noriaki Matsushima, Institute of Social and Economic Research, Osaka University, 6-1 Mihogaoka, Ibaraki, Osaka 567-0047, Japan. Phone: (81)-6-6879-8571. Fax: (81)-6-6879-8583. E-mail: nmatsush@iser.osaka-u.ac.jp

${ }^{\ddagger}$ Koki Arai, Competition Policy Research Center, Japan Fair Trade Commission, 1-1-1 Kasumigaseki, Chiyoda, Tokyo 100-8987, Japan. E-mail: koki_arai@jftc.go.jp

${ }^{\S}$ Ikuo Ishibashi, Osaka School of International Public Policy, Osaka University, 1-31 Machikaneyama, Toyonaka, Osaka 560-0043, Japan. E-mail: ishibashi@osipp.osaka-u.ac.jp

๑ Fumio Sensui, Graduate School of Law, Kobe University, 2-1 Rokkodai, Nada, Kobe, Hyogo, 657-8501, Japan. E-mail: sensui@kobe-u.ac.jp 


\section{Introduction}

The Japan Fair Trade Commission (hereinafter, "JFTC") decided to conduct a hearing into Microsoft Japan (hereinafter, "MS") on September 1, 2004, and delivered its decision in accordance with the Antimonopoly Act on September 16, 2008. The JFTC found the following violation of the Act. When MS directly negotiated with personal computer production/sales firms in Japan from January 1, 2001, to July 31, 2004, to enter into contracts licensing OEMs (Original Equipment Manufacturers) sales of MS Windows ("OS"), it forced the licensed OEM suppliers (hereinafter, "OEM suppliers") to pledge not to file lawsuits against MS or other licensees on the grounds that Windows infringes a patent right (non-assertion of patents provisions; hereinafter, these provisions are referred to as "NAP provisions"). In addition, MS set contract terms with OEM suppliers that would unduly restrain their business activities. MS abandoned the NAP provisions in direct contracts from August 1, 2004, but the NAP provisions in contracts that were to expire by July 31, 2004, remained in effect even after August 2004. The JFTC ruled that these actions had a negative impact on fair competition in the PC/AV (Personal Computer/Audio Visual) technology exchange market, prevented fair competition under Paragraph 13 (Trading on Restrictive Terms) of the Unfair Trade Practices (JFTC notice \#15 in 1982) and violated Article 19 of the Antimonopoly Act.

In the MS case, the main issues were as follows.

1. Whether OEM suppliers were forced to enter into direct contracts containing NAP provisions.

2. Whether OEM suppliers were very likely to become less motivated in their R\&D activities concerning PC/AV technologies before July 31, 2004.

3. Whether OEM suppliers were very likely to become less motivated in their R\&D activities concerning PC/AV technologies even after August 1, 2004.

4. Whether the NAP provisions would have a negative impact on competition in PC/AV technology trading or PC markets. 
5. Whether the NAP provisions were justified.

6. Whether a cease and desist order was appropriate.

For the purpose of this paper, we set up a simple theoretical model to examine issues 2 to 4 above and investigate whether the JFTC decision was appropriate. This paper is organized as follows. Section 2 briefly describes the NAP provisions that provide incentives for our study and related articles. Section 3 explains the model. Section 4 sets out the main results. Section 5 compares the analytical results with the information described in Section 2. Section 6 concludes the paper.

\section{Motivating case and related articles}

\subsection{The MS case}

The outline of the NAP provisions in Windows OEM sales contracts is as follows (the text is taken from the JFTC decision)

Content of the NAP provisions The NAP provisions in the direct contract entered into in 2001 are set forth in (d) of Article 8 of BTD (Microsoft Business Terms Document for OEM customers) for Large Accounts with Third-Party Installer Rights and have the following content, generally speaking.

If an invention used in the "product" licensed to OEM suppliers based on the license agreement or in the "product" version licensed to OEM suppliers in accordance with the license agreement is also employed in a future product, a replacement-use product or successor product of such a "product," the OEM supplier shall agree that (A) it will not file a lawsuit and (B) it will not initiate action against, prosecute, support, or participate in any kind of judicial, administrative, or other proceedings against Microsoft and its affiliate firms or their licensees in terms of infringement of the "OEM supplier's patent" that might arise in the "immunity period" resulting from production, use, sales, or distribution of the future product, replacement-use product, or successor products.

On the surface, this provision appears to be advantageous only for MS, but it may lead to technology leakage. If MS improves its OS technologies using an OEM supplier's R\&D outcomes, it may yield positive impacts both for MS and for OEM suppliers, but the possible 
effects of such technology leakage are not simple. This is because such positive impacts would vary, depending on how they spill out and who would benefit from them. In fact, MS raised the following objection.

It is unreasonable to recognize the NAP provisions as a violation of the Antimonopoly Act for the following reasons.

The NAP provisions are reasonable provisions commonly used by technologyrelated firms, including those in the AV consumer electronics industry, to mitigate risks of patent infringement lawsuits and reduce the costs necessary to mitigate such risks while disseminating new technologies. Because the NAP provisions would, by definition, prevent patent infringement lawsuits, they could potentially reduce corporate willingness to engage in R\&D efforts. In principle, if such an abstract possibility is illegal, this is tantamount to recognizing that the NAP provisions are in themselves illegal. However, as mentioned above, they have reasonable objectives. If the JFTC recognizes as illegal the NAP provisions that are widely used in the industry, specific reasons are necessary under competition law to justify this decision. If the JFTC regards the NAP provisions as illegal without specific criteria to justify the illegality of the NAP provisions, our industry, which has been using the NAP provisions, will inevitably become confused. This will have significantly detrimental effects and seriously confuse legitimate intellectual property licensing practices. In addition, OEM suppliers have also benefited from the NAP provisions over many years because they have engaged in business operations without concern for patent lawsuits. OEM suppliers expect the NAP provisions to apply to themselves and other OEM suppliers. The JFTC's decision to overturn the NAP provisions will destroy such expectations.

Furthermore, the NAP provisions are an important element of the compensation that OEM suppliers provide in return for licenses of the Windows series. The NAP provisions also serve to maintain OEM suppliers' royalty payments at a low level. For this reason, if the JFTC decision is applied retroactively, it would void the NAP provisions. All OEM suppliers that wish to void the NAP provisions while benefiting from low royalty payments should return such profits to MS. Without such a provision, the JFTC decision would be unjust.

It is obviously necessary to pay due attention to international harmonization when enforcing competition law. MS employs NAP provisions worldwide. Corporations all over the world, including Japanese firms, also use NAP provisions on a global scale. In such situations, the competition authority should avoid problems in applying a legal principle to the same kind of trading practices. Without these NAP provisions, global corporations, including the so-called AV consumer elec- 
tronics industry, face uncertainty when they plan licensing or trading practices in accordance with applicable legal standards.

As mentioned earlier, this trial was to examine whether the NAP provisions violated the Antimonopoly Act, not to judge their legality. For this reason, the arguments of MS were ruled to be inappropriate. Considering these facts, we analyze the effects of MS' NAP provisions by establishing a simple model to describe the situation detailed above.

\subsection{Main results and related work}

We now describe the model setting and the results in this paper. This article assumes that MS is an upstream firm while OEM suppliers are downstream firms. A monopoly upstream firm supplies an input to two downstream firms. The two downstream firms supply their final products to consumers and engage in cost-reducing R\&D. We assume that if the upstream firm employs NAP provisions, it freely incorporates R\&D outcomes into its inputs. Incorporation of $R \& D$ improves the efficiency of the downstream firms' production. We interpret the introduction of NAP provisions as a source of technology spillover. The theoretical model yields the following result. Using the technologies of the two downstream firms is optimal for the upstream firm as long as the degree of technology spillover is small. If the spillover is large, the upstream firm should not introduce NAP provisions from the viewpoint of profit. In addition, if the ex ante cost difference between the downstream firms is significant, such technology spillover erodes both the profit of the efficient downstream firm and social welfare.

We review several articles related to our paper. A seminal article in the field of research joint venture including spillover effects is that of d'Aspremont and Jacquemin (1988). They show that cooperative behavior can play a positive role in oligopoly industries. The positive and normative effects of cooperative R\&D are examined by Suzumura (1992), who finds that, in the presence of sufficiently large R\&D spillovers, neither noncooperative nor cooperative equilibria achieve even second-best R\&D levels. In the absence of spillover effects, however, while the cooperative $R \& D$ level remains socially insufficient, the noncooperative level may overshoot the first- and second-best levels of R\&D. 
Some articles discuss technology investments in oligopoly models with vertical relations. Ishii (2004) extends the model of Suzumura (1992). He examines the effects of cooperative $R \& D$ in two vertically related duopolies, which are two final-good manufacturers and two input suppliers, with horizontal and vertical spillovers. Vertical R\&D cartels yield a larger social surplus than noncooperative R\&D. If the horizontal spillover rate between the input suppliers is insufficiently high, vertical R\&D cartels yield a larger social surplus than horizontal ones. Regarding information firewalls, Milliou (2004) considers the case in which information flows from a downstream nonintegrated firm to the downstream division of a vertically integrated firm via its upstream subsidiary. In a setting where both the integrated and the nonintegrated firms engage in cost-reducing $\mathrm{R} \& \mathrm{D}$ and compete in the product market, she shows that the impact of the R\&D information flow on innovation, output, and profits is positive for the integrated firm and negative for the nonintegrated firm. These papers do not consider the structures of technology spillover to be exogenously given. ${ }^{1}$

The following papers consider market structures in which downstream firms determine the degree of technology spillover, but not vertical market structures. ${ }^{2}$ The role of a research joint venture is analyzed by Poyago-Theotoky (1999), who shows that when spillovers of information are treated as endogenous, firms never disclose any information when determining the degree of R\&D spillover noncooperatively. Gil-Moltó et al. (2005) investigate the effect of technology distance between two firms engaging in cost-reducing R\&D investments with technology spillover. ${ }^{3}$ In their model, the technology distance is endogenously determined They show that the two firms are noncooperatively interested in using very similar (or the same) R\&D technologies in order to obtain a very high degree of spillovers. Milliou (2009) also extends the discussion in Poyago-Theotoky (1999) by changing the timing of the decisions concerning the degree of technology spillover. She shows that even if each firm protects its technology without cost, it sometimes chooses not to protect the outcomes of its $\mathrm{R} \& \mathrm{D}$

\footnotetext{
${ }^{1}$ Versaevel and Vencatachellum (2009) incorporate strategic delegation into a model with technology leakage.

${ }^{2}$ Moreover, in our paper, the upstream monopolist determines the degree of technology spillover.

${ }^{3}$ Piga and Poyago-Theotoky (2005) investigate this matter in the context of spatial competition.
} 
investments because firms enjoy higher total cost reduction without such protection. ${ }^{4}$

\section{The model}

Two downstream firms supply their final products to consumers. A monopoly upstream firm supplies an input to the two downstream firms. The downstream and upstream firms represent OEM suppliers and MS, respectively, as described in the previous sections. Each downstream firm needs one unit of input to produce one unit of final product. The upstream firm offers a common wholesale price, $w$, to the downstream firms. The marginal cost of the upstream firm is $c_{u}$, which is a positive constant.

To simplify the analysis, we assume that the products of the downstream firms are homogeneous and that the firms compete in quantity. The inverse demand function for the final products is given as:

$$
p=a-x_{1}-x_{2},
$$

where $p$ is market price, $a$ is a positive constant, and $x_{k}$ represents the output of downstream firm $k(k=1,2)$. Note that we assume $a$ to be large enough to secure an interior solution in equilibrium. The constant marginal cost of downstream firm $k$ is given as:

$$
c_{k}=\bar{c}_{k}-e_{k}-\gamma_{k} e_{j}
$$

where $\bar{c}_{k}$ is the ex ante marginal cost, $e_{k}$ and $e_{j}$ represent the effort levels of downstream firms $k$ and $j$, respectively, and $\gamma_{k}$ represents the degree of R\&D spillover from downstream firm $j$ to $k(k, j=1,2, j \neq k)$. The ex ante marginal costs of the firms are $\bar{c}_{1}=c$ and $\bar{c}_{2}=c+d$, where $c$ and $d$ are positive constants. That is, downstream firm 1 is more efficient than downstream firm 2. These effort levels are endogenously determined by the downstream firms. When downstream firm $k$ makes an effort $e_{k}$, it incurs an investment cost of $\phi e_{k}^{2}$ where $\phi$ is a positive constant. We impose the following assumptions.

Assumption 1 We assume that $\phi \geq 1$ to satisfy the second-order conditions of optimal $e_{k}$

\footnotetext{
${ }^{4}$ In Milliou (2009), an asymmetry between a firm's outgoing spillovers and its incoming spillovers can occur. This property is different from the previous papers.
} 
$(k=1,2)$. We also assume that $d \leq(a-c)(12 \phi-7) /(42 \phi-7)$ to ensure that the quantities supplied by the downstream firms are positive.

The upstream firm is able to choose the degree of $\mathrm{R} \& \mathrm{D}$ spillover, $\gamma_{k}(k=1,2)$. If the upstream firm absorbs technology from downstream firm $k$, the degree of $\mathrm{R} \& \mathrm{D}$ spillover from downstream firm $k$ to $j$ becomes $\gamma$ where $\gamma$ is a positive constant $(0 \leq \gamma \leq 1)$. This assumption captures the following technology leakage. Technology from a downstream firm (an OEM supplier) is incorporated into the input of the upstream firm (OS produced by MS). The incorporation positively influences the marginal cost of another downstream firm (an OEM supplier). This means that this technological improvement in the input (OS) solves production problems that downstream firms (OEM suppliers) face. In this case, the upstream firm has four options regarding absorption of technology from downstream firms: (i) not absorbing the technology, (ii) absorbing the technology from downstream firm 1, (iii) absorbing the technology from downstream firm 2, and (iv) absorbing the technologies from both downstream firms. Note that depending on the upstream firm's decision concerning technology absorption, asymmetric R\&D spillover can occur. We also suppose that the upstream firm can commit to this choice. That is, given the choice by the upstream firm, each downstream firm engages in $R \& D$ investment. Figure 1 shows the market structure in this model.

\section{[Figure 1]}

The decision-making process in this setting is as follows. First, the upstream firm decides the technological source from which it obtains the technology. Second, each downstream firm decides its investment level $e_{k}$. Third, the upstream firm decides the wholesale price $w$. Finally, each downstream firm decides its output $x_{k}$.

\section{Analysis}

We solve the game by backward induction.

In the final stage, given $\gamma_{k}, e_{k}(k=1,2)$, and $w$, the profit of each downstream firm is 
as follows:

$$
\begin{aligned}
& \pi_{1}=\left(a-x_{1}-x_{2}-\left(c-e_{1}-\gamma_{2} e_{2}\right)-w\right) x_{1}-\phi e_{1}^{2}, \\
& \pi_{2}=\left(a-x_{1}-x_{2}-\left(c+d-e_{2}-\gamma_{1} e_{1}\right)-w\right) x_{2}-\phi e_{2}^{2} .
\end{aligned}
$$

On the basis of the maximization condition for each downstream firm, the output of each downstream firm is calculated as follows:

$$
\begin{aligned}
& x_{1}\left(\gamma_{1}, \gamma_{2}, e_{1}, e_{2}, w\right)=\frac{a-c+d+\left(2-\gamma_{1}\right) e_{1}-\left(1-2 \gamma_{2}\right) e_{2}-w}{3} \\
& x_{2}\left(\gamma_{1}, \gamma_{2}, e_{1}, e_{2}, w\right)=\frac{a-c-2 d+\left(2-\gamma_{2}\right) e_{2}-\left(1-2 \gamma_{1}\right) e_{1}-w}{3} .
\end{aligned}
$$

The profit function of the upstream firm is given as:

$$
\begin{aligned}
\pi_{u} & =\left(w-c_{u}\right)\left(x_{1}\left(\gamma_{1}, \gamma_{2}, e_{1}, e_{2}, w\right)+x_{2}\left(\gamma_{1}, \gamma_{2}, e_{1}, e_{2}, w\right)\right) \\
& =\frac{\left(w-c_{u}\right)\left(2 a-2 c-d+\left(1+\gamma_{1}\right) e_{1}+\left(1+\gamma_{2}\right) e_{2}-2 w\right)}{3} .
\end{aligned}
$$

In the third stage, the upstream firm sets the optimal $w$ :

$$
w\left(\gamma_{1}, \gamma_{2}, e_{1}, e_{2}\right)=\frac{2\left(a-c+c_{u}\right)-d+\left(1+\gamma_{1}\right) e_{1}+\left(1+\gamma_{2}\right) e_{2}}{4} .
$$

By using the aforementioned calculation result on $x_{k}\left(\gamma_{1}, \gamma_{2}, e_{1}, e_{2}, w\right)$ and $w\left(\gamma_{1}, \gamma_{2}, e_{1}, e_{2}\right)$, we calculate the investment levels and obtain the following result:

$$
\begin{aligned}
& e_{1}\left(\gamma_{1}, \gamma_{2}\right)=\frac{\left(7-5 \gamma_{1}\right)\left(6\left(2\left(a-c-c_{u}\right)+5 d\right) \phi-\left(7-5 \gamma_{2}\right)\left(\left(1-\gamma_{2}\right)\left(a-c-c_{u}\right)+\gamma_{2} d\right)\right)}{864 \phi^{2}-6\left(\left(7-5 \gamma_{1}\right)^{2}+\left(7-5 \gamma_{2}\right)^{2}\right) \phi+\left(7-5 \gamma_{1}\right)\left(7-5 \gamma_{2}\right)\left(1-\gamma_{1} \gamma_{2}\right)} \\
& e_{2}\left(\gamma_{1}, \gamma_{2}\right)=\frac{\left(7-5 \gamma_{2}\right)\left(6\left(2\left(a-c-c_{u}\right)-7 d\right) \phi-\left(7-5 \gamma_{1}\right)\left(\left(1-\gamma_{1}\right)\left(a-c-c_{u}\right)-d\right)\right)}{864 \phi^{2}-6\left(\left(7-5 \gamma_{1}\right)^{2}+\left(7-5 \gamma_{2}\right)^{2}\right) \phi+\left(7-5 \gamma_{1}\right)\left(7-5 \gamma_{2}\right)\left(1-\gamma_{1} \gamma_{2}\right)}
\end{aligned}
$$

Substituting $e_{k}\left(\gamma_{1}, \gamma_{2}\right)(k=1,2)$ into the profit functions of the downstream firms, we have:

$$
\begin{aligned}
& \pi_{1}\left(\gamma_{1}, \gamma_{2}\right) \equiv \frac{\phi\left(144 \phi-\left(7-5 \gamma_{1}\right)^{2}\right)\left(e_{1}\left(\gamma_{1}, \gamma_{2}\right)\right)^{2}}{\left(7-5 \gamma_{1}\right)^{2}} \\
& \pi_{2}\left(\gamma_{1}, \gamma_{2}\right) \equiv \frac{\phi\left(144 \phi-\left(7-5 \gamma_{2}\right)^{2}\right)\left(e_{2}\left(\gamma_{1}, \gamma_{2}\right)\right)^{2}}{\left(7-5 \gamma_{2}\right)^{2}} .
\end{aligned}
$$

The profit of the upstream firm is

$$
\pi_{u}\left(\gamma_{1}, \gamma_{2}\right) \equiv \frac{216 \phi^{2} K^{2}}{\left[864 \phi^{2}-6\left(\left(7-5 \gamma_{1}\right)^{2}+\left(7-5 \gamma_{2}\right)^{2}\right) \phi+\left(7-5 \gamma_{1}\right)\left(7-5 \gamma_{2}\right)\left(1-\gamma_{1} \gamma_{2}\right)\right]^{2}},
$$


where $\left.K \equiv 12\left(2\left(a-c-c_{u}\right)-d\right) \phi-\left(a-c-c_{u}\right) \sum_{i=1}^{2}\left(1-\gamma_{i}\right)\left(7-5 \gamma_{i}\right)+\left(\left(7-5 \gamma_{1}\right)-\gamma_{2}\left(7-5 \gamma_{2}\right)\right) d\right)$. The consumer surplus and the social surplus are:

$$
\begin{gathered}
C S\left(\gamma_{1}, \gamma_{2}\right)=\frac{\left(x_{1}\left(\gamma_{1}, \gamma_{2}\right)+x_{2}\left(\gamma_{1}, \gamma_{2}\right)\right)^{2}}{2}=\frac{\pi_{u}\left(\gamma_{1}, \gamma_{2}\right)}{3}, \\
S W\left(\gamma_{1}, \gamma_{2}\right) \equiv C S\left(\gamma_{1}, \gamma_{2}\right)+\pi_{u}\left(\gamma_{1}, \gamma_{2}\right)+\sum_{i=1}^{2} \pi_{i}\left(\gamma_{1}, \gamma_{2}\right) .
\end{gathered}
$$

We must compare the profits of the upstream firm in the four cases: (i) $\gamma_{1}=\gamma_{2}=0$, (ii) $\gamma_{1}=0$ and $\gamma_{2}=\gamma$, (iii) $\gamma_{1}=\gamma$ and $\gamma_{2}=0$, (iv) $\gamma_{1}=\gamma_{2}=\gamma$. From the comparison, we find that $\pi_{u}(\gamma, \gamma)$ is the largest value among the four cases if and only if $\gamma \leq 2 / 5$ and that $\pi_{u}(0,0)$ is the largest value among the four cases if and only if $\gamma \geq 2 / 5$ (the calculation is available upon request). This is summarized in Proposition 1.

Proposition 1 It is optimal for the upstream firm to use the technologies of both downstream firms if and only if $\gamma \leq 2 / 5$. It is optimal for the upstream firm to do nothing if and only if $\gamma \geq 2 / 5$. If $\gamma=2 / 5$, it is indifferent for the upstream firm to choose one of the four cases.

From the above comparison, we only have to compare cases (i) and (iv). Comparing these two cases, we have the following proposition:

Proposition $2 C S(\gamma, \gamma)>C S(0,0)$ if and only if $\gamma<2 / 5 . \pi_{2}(\gamma, \gamma)>\pi_{2}(0,0)$ for any $\gamma$ and $\phi . \pi_{1}(\gamma, \gamma)>\pi_{1}(0,0)$ if and only if $d<\tilde{d}_{p}(\gamma, \phi)$ such that $\tilde{d}_{p}(\gamma, \phi)$ satisfies $\pi_{1}(\gamma, \gamma)=$ $\pi_{1}(0,0) . \quad S W(\gamma, \gamma)>S W(0,0)$ if and only if $d<\tilde{d}_{w}(\gamma, \phi)$ such that $\tilde{d}_{w}(\gamma, \phi)$ satisfies $S W(\gamma, \gamma)=S W(0,0)$.

The difference between $\pi_{1}(\gamma, \gamma)$ and $\pi_{1}(0,0)$ is shown in the following figure (this is the case of $\phi=3 / 2$ ).

\section{[Figure 2]}

The difference between $S W(\gamma, \gamma)$ and $S W(0,0)$ is shown in the following figure (this is the case of $\phi=3 / 2)$.

[Figure 3] 
From the viewpoint of the downstream firms, the investment reduction through the technology spillover does not necessarily have a negative impact on their profitability. We now briefly explain the reason for this property. Basically, the downstream firms have incentives to make excessive investments to prevail over their competitors because the competition structure between the downstream firms is strategic substitution. This incentive will be reduced because of the technology leakage determined by the upstream firm. The mitigation of this intensive investment competition has a positive impact on the downstream firms. In particular, it has a more advantageous impact on the inefficient downstream firm with less incentive for $R \& D$. This is because the benefit of cost reduction for a downstream firm is proportional to its quantity supplied, whereas the investment cost does not depend on this quantity as it does in the standard setting of R\&D. Anticipating this asymmetry of technological spillover, the efficient firm reduces its R\&D investment more than the inefficient firm does. When the ex ante cost difference between the downstream firms is large, the diminished incentive of the efficient firm for R\&D investment decreases its profit.

The upstream firm's decision concerning this technology absorption has two effects: the strategic effect mentioned above, and the direct effect of technology leakage. The former decreases the total quantity supplied but the latter increases it. The latter positive effect is small when the spillover effect is large ( $\gamma$ is large). We briefly explain the reason. The larger the degree of spillover effect, the smaller are the equilibrium effort levels of the downstream firms. The total amount of technology leakage is proportional to the equilibrium effort levels. The two properties imply that the positive effect of a marginal increase in the degree of spillover effect becomes weak as the degree of spillover effect becomes large. Therefore, when the degree of spillover effect is large, the technology spillover caused by the decision of the upstream firm decreases the total quantity supplied by the downstream firms. Anticipating this negative effect, the upstream firm does not absorb technologies from the downstream firms when the degree of spillover effect is large. Note that the decrease in this total quantity supplied also harms consumers.

The effect of technology absorption on the social surplus can be explained by the combina- 
tion of the abovementioned effects. When the ex ante cost heterogeneity is large, technology absorption by the upstream firm has a negative impact on the efficient firm. When the degree of spillover effect is large, the technology absorption has negative impacts on the upstream firm and consumers. The right-hand side of Figure 3 shows the combination of those two properties.

\section{$5 \quad$ Interpretation of analytical results}

We derive the following results. It is only optimal for the upstream firm (MS) to use technology from both efficient and inefficient downstream firms (OEM suppliers) if the degree of technology spillover is small. If MS may not commit "not to take over technology after investment," it will exploit OEM suppliers' investment efforts. For this reason, if the leakage is large, MS should not introduce NAP provisions in some cases. If the preexisting cost gap is significant, technology leakage will erode the profits of the efficient OEM supplier. We now interpret the result.

\subsection{The JFTC decision}

Arguments by the respondent (MS) (from Section 1) The NAP provisions are reasonable provisions commonly used among technology-related firms, including those in the AV consumer electronics industry, to mitigate risks of patent infringement lawsuits and reduce the cost necessary to mitigate such risks while disseminating new technologies. Because the NAP provisions would, by definition, prevent patent infringement lawsuits, they could potentially reduce corporate willingness to engage in $R \& D$ efforts. In principle, if such an abstract possibility is illegal, this is tantamount to recognizing that the NAP provisions are in themselves illegal.

Decision by hearing examiners This hearing is to examine whether the NAP provisions would violate the Antimonopoly Act and does not make decisions concerning the legality of the NAP provisions. For this reason, the arguments made by MS are inappropriate. 


\subsection{Applicability}

The NAP provisions generally suggest that if MS may use OEM technologies, it is assumed to employ a large quantity of OEM technologies. On the other hand, from the viewpoint of OEM suppliers, a quality gap may erode the profits of a high-quality OEM supplier; incentives for investment may also be compromised with a cost gap between the efficient and inefficient firms. In other words, if we discuss the contracts containing these provisions in relation to the Antimonopoly Act, and OEM suppliers have a technology gap, then it is necessary to pay due attention to the possibility that the NAP provisions erode the profits of efficient OEM suppliers or interfere with OEM suppliers' incentives to invest. This is also related to OEM suppliers' viewpoints expressed in the JFTC decision.

\section{The JFTC decision (taken from the hearing examiners' judgment, page} 114, JFTC Decisions) As recognized in 3(1)A above, because the NAP provisions will be applicable in the future, they will apply to licensed products as well as future products and will be in effect for a very long time. In addition, because a wide variety of patent rights may fall under free licenses as a result of the expansion of the Windows series capabilities, the JFTC determines as follows. [...] MS has expanded/enhanced the AV capabilities of Windows series, and several OEM suppliers have expressed their concern that the NAP provisions would have an impact on their patent rights in relation to their own PC AV technologies (Panasonic has expressed concerns about AV technology patents in general; Sony has concerns about the standard specifications of "MPEG-1," "MPEG2," "IEEE1394," "MPEG-4" AV, digital video broadcasting and its multimedia platform; Toshiba has expressed concerns about the standard specifications of "IEEE1394," "MPEG-2" AV and "MPEF-4" AV-Attachment (1), Written Statement (2), Respondent's Brief (3)) and they requested that MS remove the NAP provisions. From these viewpoints, while recognizing that their PC AV technologies would be incorporated into the Windows series, OEM suppliers had no choice but to develop their own PC AV technologies.

We have shown that the diminishment in the efficient firm's incentive for R\&D decreases its profit if the ex ante cost difference between the downstream firms is large. Because the JFTC decision recognizes that large corporations such as Panasonic, Sony, and Toshiba and perhaps other highly efficient firms had concerns about NAP provisions, the above analysis 
is on point in its theoretical implications. In response to NAP provisions, Sharp and Sotec did not request MS to remove or amend the NAP provisions; Sharp had few patent rights in PC-use OS and Sotec specialized in selling PCs without customizing the Windows series.

As for the negative impacts of NAP provisions on competition policies, it is suggested that a dominant firm in the PC OS market such as MS would occupy a more advantageous position than new entrants that do not use NAP provisions. However, if NAP provisions are "reasonable provisions commonly used among technological firms, including the AV consumer electronics industry," it is difficult to imagine new entrants not using NAP provisions in reality. Furthermore, concerning the negative impacts of NAP provisions on competition policies, MS may have had problems in introducing the NAP provisions or negotiating possible amendments with OEM suppliers; however, this paper does not analyze this topic.

\section{Conclusion}

This paper analyzes a theoretical background to the JFTC decision on the MS case in which JFTC decided to commence hearing proceedings on September 1, 2004, delivering its decision on September 16, 2008, in accordance with the Antimonopoly Act. This JFTC decision ruled that the Act had been violated in the following way. When MS directly negotiated with personal computer production/sales firms in Japan from January 1, 2001, to July 31, 2004, to enter into contracts licensing OEM sales of MS Windows ("OS"), it forced the licensed OEM suppliers to accept NAP provisions. MS set contract terms with OEM suppliers that would unduly restrain OEM suppliers' business activities. Some issues in the MS case remain in dispute. We analyze the case by setting up simple theoretical models, focusing on the following three points:

1. Whether OEM suppliers were very likely to become less motivated in their R\&D activities concerning PC/AV technologies before July 31, 2004.

2. Whether OEM suppliers were very likely to become less motivated in their R\&D activities concerning PC/AV technologies even after August 1, 2004. 
3. Whether NAP provisions have a negative impact on competition in PC/AV technology trading or PC markets.

The theoretical model yielded the following result. If the technology of an OEM supplier is introduced into MS' OS, and the marginal cost of the other OEM supplier decreases, then using the technologies of these two OEM suppliers is optimal for MS as long as technology leakage is small. If technology leakage is large, MS should not introduce NAP provisions. In addition, if the preexisting cost gap is significant, technology leakage will erode the profit of the efficient OEM supplier.

This analysis implies that OEM suppliers face different impacts depending on their position in the downstream market and that OEM suppliers should offer factual evidence that considers such perspectives. For example, if OEM suppliers have a technology gap, they should clarify possible problems in competition policies, because these problems might damage the profits of efficient OEM suppliers or remove their incentive to invest. On the other hand, our analysis also reveals that quantification of these impacts requires careful review.

It may be necessary to examine how to respond to the dominant position of MS in the market, although this paper does not cover such a topic. The JFTC decision argues that MS has a problem because it "keeps using" NAP provisions despite having achieved dominance in the market. The decision also indicates that it is a problem that a dominant supplier uses NAP provisions and that the network effect would serve to further enhance MS' dominant status. Antimonopoly Act experts often state that it is no problem, from the viewpoint of the Antimonopoly Act, for new entrants to adopt such an approach because it encourages competition, but it becomes a problem if it is used by a supplier with dominant status. 


\section{References}

[1] d'Aspremont, Claude and Jacquemin, Alexis, 1988. Cooperative and noncooperative R\&D in duopoly with spillovers, American Economic Review 78, 1133-37.

[2] María José Gil-Moltó, Nikolaos Georgantzís, Vicente Orts, 2005. Cooperative R\&D with endogenous technology differentiation Journal of Economics and Management Strategy $14,461-476$.

[3] Ishii, Akira, 2004. Cooperative R\&D between vertically related firms with spillovers. International Journal of Industrial Organization 22, 1213-1235.

[4] Milliou, Chrysovalantou, 2004. Vertical integration and R\&D information flow: is there a need for 'firewalls'? International Journal of Industrial Organization 22, 25-43.

[5] Milliou, Chrysovalantou, 2009. Endogenous protection of R\&D investments. Canadian Journal of Economics 42, 184-205.

[6] Piga, Claudio and Poyago-Theotoky, Joanna, 2005. Endogenous R\&D spillovers and locational choice. Regional Science and Urban Economics 35, 127-139.

[7] Poyago-Theotoky, Joanna, 1999. A note on endogenous spillovers in a non-tournament R\&D duopoly. Review of Industrial Organization 15, 253-262.

[8] Suzumura, Kotaro, 1992. Cooperative and noncooperative R\&D in oligopoly with spillovers. American Economic Review 82, 1307-1320.

[9] Versaevel, Bruno and Vencatachellum, Désiré, 2009. R\&D delegation in a duopoly with spillovers, The B.E. Journal of Economic Analysis 85 Policy (Contributions) 9, Article 55. 


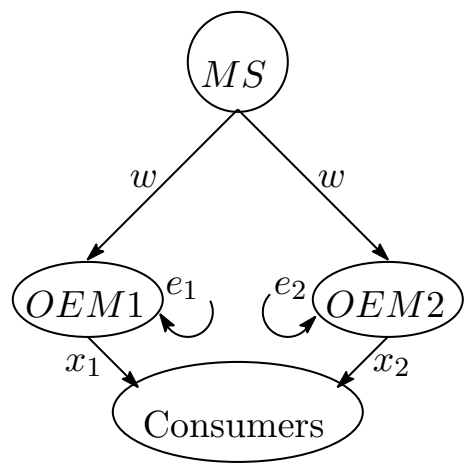

No absorption

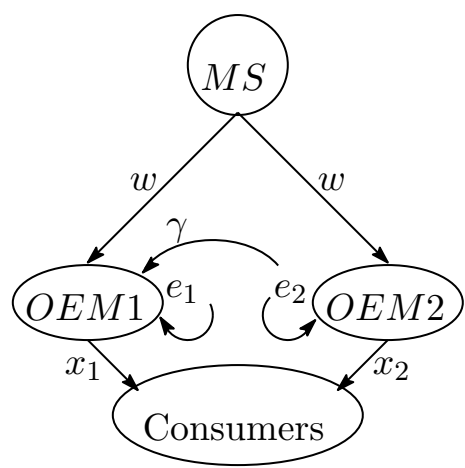

Absorbing the technology of firm 2

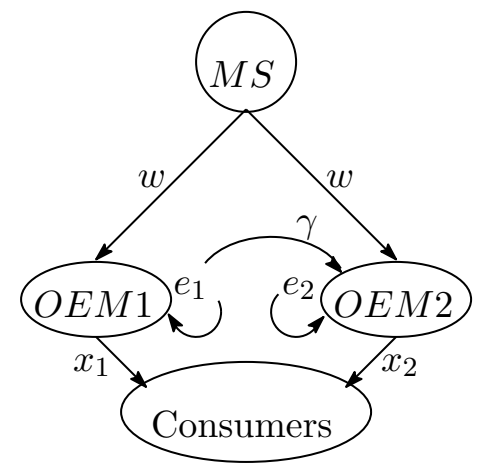

Absorbing the technology of firm 1

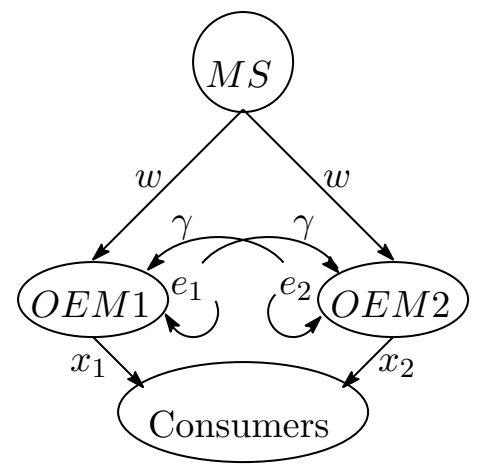

Absorbing both technologies

Figure 1: The market structure 

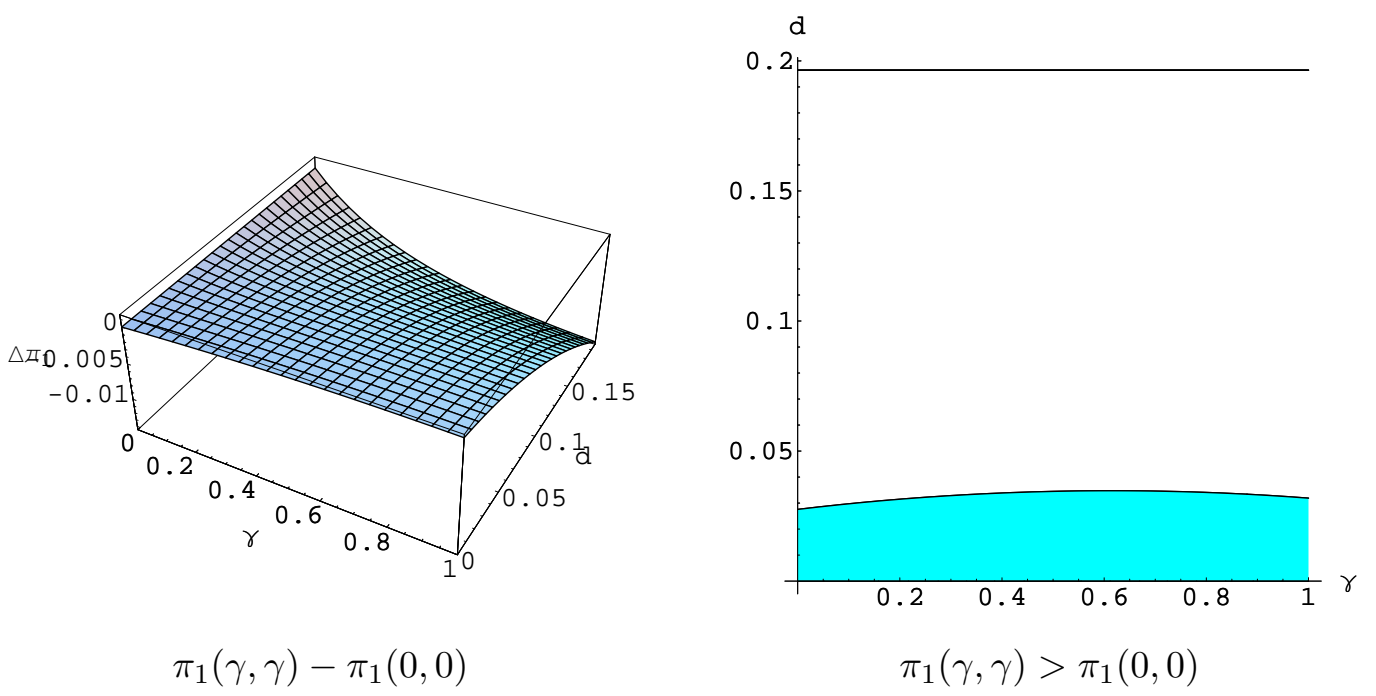

Figure 2: The effect of technology spillover on the efficient OEM supplier

(Left-hand) $\quad x$-axis: $\gamma, y$-axis: $d, z$-axis: $\pi_{1}(\gamma, \gamma)-\pi_{1}(0,0)$,

(Right-hand) $\quad x$-axis: $\gamma, y$-axis: $d$, Shaded region: $\pi_{1}(\gamma, \gamma)>\pi_{1}(0,0)$. 

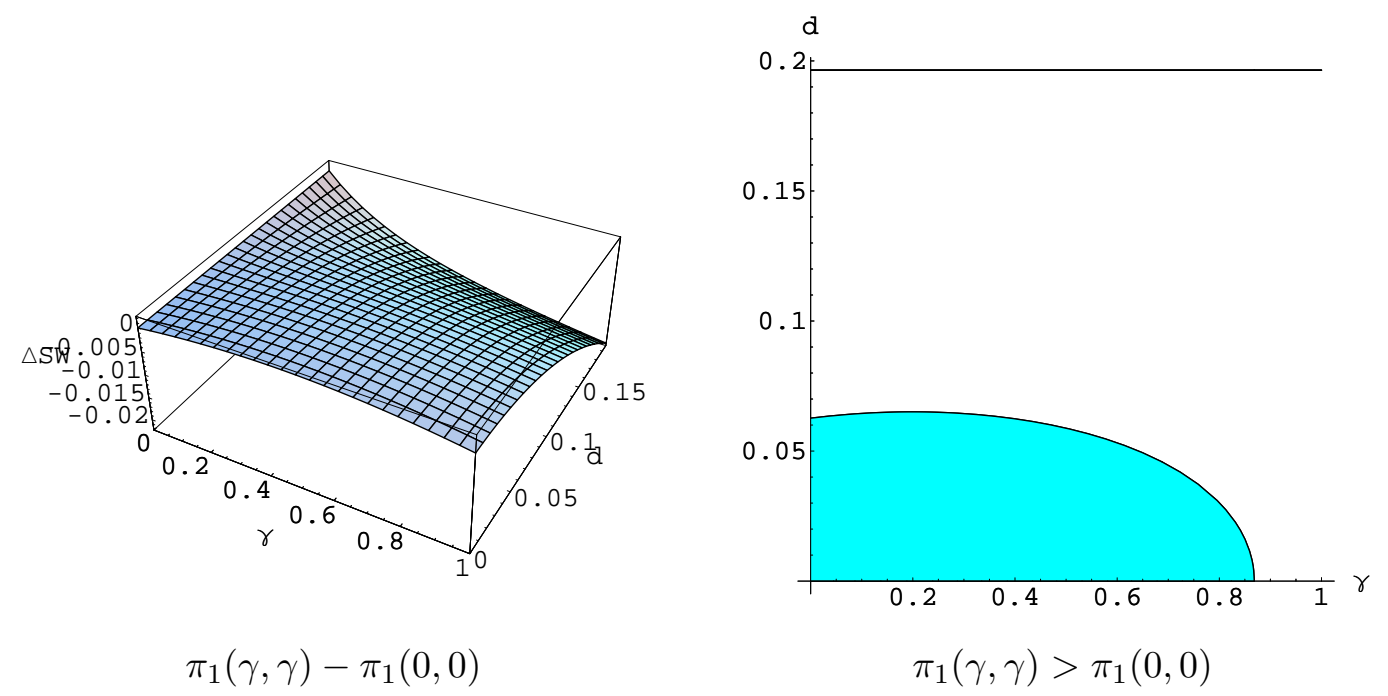

Figure 3: The effect of technology spillover on the social surplus

(Left-hand) $\quad x$-axis: $\gamma, y$-axis: $d, z$-axis: $S W(\gamma, \gamma)-S W(0,0)$,

(Right-hand) $\quad x$-axis: $\gamma, y$-axis: $d$, Shaded region: $S W(\gamma, \gamma)>S W(0,0)$. 